\title{
The mortality of amphibole miners in South Africa, 1946-80
}

\author{
G K Sluis-Cremer, F D K Liddell, W P D Logan, B N Bezuidenhout
}

\begin{abstract}
A cohort was established in 1981 of all 7317 white male employees in the amosite and crocidolite mines in South Africa whose names had appeared in the personnel records (initiated between 1945 and 1955) of the major companies. Some of the men had been employed as early as 1925 , but only $8 \%$ had had more than 10 years of service. Three subcohorts were defined: 3212 men whose only exposure to asbestos was to amosite; 3430 exposed to crocidolite; and 675 to both amphiboles. No deaths or losses to view occurred before 1946, and 5925 men $(81 \%)$ were known to be alive at the end of 1980 . Losses to view numbered $167(2 \%)$, and there had been 1225 deaths $(17 \%)$, an excess of 331 over the number of deaths expected on the basis of the mortality of all white South African males. The fibre related excesses were of mesothelioma, lung cancer, and other respiratory diseases, but there were other excesses perhaps mainly related to socioeconomic factors including lifestyle. When cause of death was determined according to "best evidence" (after study of clinical, radiological, biopsy, and necropsy reports in conjunction with the death certificate), there were 30 deaths due to mesothelioma ( 22 pleural, six peritoneal, two other) and 65 due to cancer of trachea, bronchus, and lung. Various analyses of these deaths showed that crocidolite had higher toxicity than amosite for lung cancer and this was most pronounced for mesothelioma; there can now be no question that crocidolite is far more
\end{abstract}

Medical Bureau for Occupational Diseases, Johannesburg, South Africa

G K Sluis-Cremer, B N Bezuidenhout

Department of Epidemiology and Biostatistics, McGill University, Montreal, Canada

F D K Liddell

10, chemin de la Tourelle, 1209 Geneva, Switzerland W P D Logan

Present address: AECI Ltd, Johannesburg, South Africa

B N Bezuidenhout dangerous than amosite at least in so far as mesothelioma is concerned. Nevertheless, crocidolite induced mesothelioma appeared only in men who had been exposed for long periods, at least 12 months, but on average about 15 years.

About $95 \%$ of asbestos production has always been of chrysotile. From the start of the industry in 1878 until the 1950s most came from Canada, but now most is mined in the former Soviet Union. The other two commercial forms of asbestos-crocidolite and amosite- have been produced in South Africa since the turn of the century. With the closure of the Western Australian crocidolite mine in 1966, South Africa became the only country to mine crocidolite; it has always had a monopoly of amosite mining.

Not surprisingly, most asbestos workers have been exposed either to chrysotile alone or to mixtures of this fibre with crocidolite or amosite, and most cohort studies have been of factory workers or end product users with mixed fibre exposures. Several cohorts of workers exposed only to chrysotile have been reported, some important ones being of miners and millers, ${ }^{1}$ asbestos cement workers, ${ }^{23}$ workers manufacturing friction products, ${ }^{4}$ gas mask filters, ${ }^{5}$ or asbestos textiles. ${ }^{6}$ These cohorts had at worst only small excesses of lung cancer (except where exposures had been exceedingly severe or in textiles) and little mesothelioma. One cohort of miners with short intense exposures to crocidolite in Western Australia, ${ }^{7}$ and five small groups of persons who assembled gas mask filters containing this fibre, ${ }^{589}$ all experienced large excesses of cancer, especially mesothelioma. One industrial group putatively exposed only to amosite also suffered severe cancer excesses, ${ }^{10}$ and another small group experienced some excesses; ${ }^{11}$ however, no study of amosite miners has been reported.

The study of a cohort of miners affords the best opportunity of examining the effects of exposure to a single type of fibre. Indeed, the evidence that exposure to chrysotile at today's concentrations causes very little cancer (except in textile manufacture) is anchored by the findings in the very large cohort of Quebec miners and millers. ${ }^{1}$ Little 
information exists about exposure either to amosite or to crocidolite alone, and so the need for study of amphibole miners is manifest.

As the major South African amosite and crocidolite producing areas, north east Transvaal and north west Cape, are some 400 miles apart, it was possible to identify cohorts of miners exposed solely to these amphibole species. The study had to be restricted, however, to white employees, because a pilot investigation on black meen and men of mixed race had shown that service records were often rudimentary and the information on death certificates largely incomplete. This is particularly unfortunate because some of those who had to be excluded were known to have been exposed to exceptionally high fibre concentrations.

The objectives of the present study were: (1) to describe the mortality experience of white miners and millers of amosite and crocidolite; and (2) to establish the relations between duration of employment and other measures of amphibole exposure and disease, especially mesothelioma and lung cancer.

\section{Materials and methods}

POPULATIONS AND EXPOSURES

The populations for study were identified from the personnel records of the South African amphibole mines. These were initiated between 1945 and 1955 at the major mines but, at a few mines with less than about 20 white employees, records were too rudimentary to use. Mines of so called Transvaal crocidolite, which operated in the same general area as the amosite mines, were also excluded. (Men who had worked only in chrysotile mines were not of course considered.)

All white male employees whose names appeared in these personnel records were identified. All demographic data, and details of each occupation, with dates of start and end, were transcribed. The medical records of the Medical Bureau of Occupational Diseases (MBOD) also contained details of service and occupation. They covered $85 \%$ of the cohort and were used to recognise service in non-asbestos mines (mostly large gold mines). Men who had worked both at a small mine with inadequate records and at a larger mine would be identified at the second, and all their service would have been recorded. Care was taken to identify amosite miners who had also worked Transvaal crocidolite, to allow treatment as a separate group. It is believed that the ascertainment of the cohort is virtually complete: it comprised 7317 white men, some of whom had commenced exposure as far back as 1925 .

From 1960, MBOD records have also contained smoking data; where possible, each subject's smoking habit was obtained.
From about 1945, environmental monitoring in South African asbestos mines has been in terms of fibre counts (see appendix). To provide a rough indication of the dust conditions to which the men were exposed, table 1 shows estimated fibre concentrations in 1945, 1960, and 1970; it does not present findings for all the asbestos mines, but includes all the larger amosite and north west Cape crocidolite mines, and excludes the crocidolite mines in Transvaal. As explained in the appendix, we calculated for each man his gross and net service, cumulative exposure to amosite and to crocidolite, and the residence time (the interval from the first exposure to death, loss to view, or end of follow up).

\section{VITAL STATUS AND CAUSES OF DEATH}

Vital status at 31 December 1980 was established by the Department of the Interior and from MBOD files and death certificates were obtained for all but six of the deceased. The cause of death assigned to the certificate by the Central Statistical Services (CSS) was classified, in terms of the then current International Classification of Diseases (ICD) rubrics, into an abridged list of 27 causes of death of prime interest (see table 5). All clinical, radiological, biopsy, and necropsy reports were then studied, in conjunction with the death certificate, to determine the cause of death according to best available evidence, also classified into the 27 study codes.

\section{METHODS OF ANALYSIS}

The primary analyses were by the subject-years method. ${ }^{12}{ }^{13}$ Subject-years (censored for those lost to view at the last date that they were known to be alive) were obtained by means of the OCMAP computer software package. ${ }^{14}$ The reference mortality experience was that for all white South African males calculated from the numbers of deaths by race, sex, age, and cause (published annually by the CSS) and corresponding mid-year population estimates (kindly made available by the CSS). The ratios of deaths observed (with cause according to death certificate) to those expected can be treated as standardised mortality ratios (SMRs) obtained by the indirect method, and confidence intervals can be calculated on the usual assumptions. ${ }^{15}$

Table 1 Fibre concentrations in selected years (fibres $/ \mathrm{ml}$ )

\begin{tabular}{lccc}
\hline & 1945 & 1960 & 1970 \\
\hline Amosite: & 150 & 56 & 40 \\
$\quad$ Surface & 14 & 6 & 4 \\
$\quad$ Underground & $30-160$ & $10-50$ & $8-30$ \\
$\begin{array}{l}\text { Crocidolite: } \\
\quad \text { Surface }\end{array}$ & $2-60$ & $2-6$ & $2-6$ \\
$\quad$ Underground & & & \\
\hline
\end{tabular}


Table 2 Numbers of men in the cohort by year of birth and year of first employment in asbestos mines

\begin{tabular}{|c|c|c|c|c|c|c|}
\hline \multirow[b]{2}{*}{ Year of birth } & \multicolumn{6}{|c|}{ Year of first asbestos exposure } \\
\hline & Before 1940 & $1941-50$ & $1951-60$ & $1961-70$ & $1971-80$ & All years \\
\hline $\begin{array}{l}1905 \text { or earlier } \\
1906-15 \\
1916-25 \\
1926-35 \\
1936-45 \\
1946 \text { or later }\end{array}$ & $\begin{array}{l}32 \\
20 \\
10 \\
- \\
-\end{array}$ & $\begin{array}{r}87 \\
108 \\
135 \\
73 \\
1 \\
-\end{array}$ & $\begin{array}{l}113 \\
358 \\
579 \\
874 \\
431 \\
-\end{array}$ & $\begin{array}{r}20 \\
143 \\
290 \\
505 \\
1063 \\
387\end{array}$ & $\begin{array}{r}-\overline{19} \\
105 \\
278 \\
574 \\
1112\end{array}$ & $\begin{array}{r}252 \\
648 \\
1119 \\
1730 \\
2069 \\
1499\end{array}$ \\
\hline All years & 62 & 404 & 2355 & 2408 & 2088 & 7317 \\
\hline
\end{tabular}

Reference mortality experience was not available before 1946, but as no person had died or was lost to view before then the effective follow up period could be restricted to January 1946 to the end of December 1980 without loss of vital information. Reference rates were not available throughout even this period for several causes of death (see footnotes to table 6), and the corresponding SMR could be calculated only for the shorter period 1949-80 (or, for pulmonary heart disease, 1968-80). National rates could not be obtained for mesothelioma or for asbestosis; those for silicosis and mine accidents were available for 196880.

It was important that analysis of mortality due to mesothelioma and bronchogenic carcinoma should be based on deaths determined according to the best evidence available. This meant that external reference mortality would not be relevant; case referent within a cohort analyses were however highly appropriate.$^{13}$ One set of referents was selected for each case according to the following criteria: each referent must have lived to a greater age than the case and been exposed to the same type of asbestos as the case. Among eligibles so defined, the referents chosen were those whose dates of birth were closest to that of the case (and always within two years). (One other restriction relating to MBOD files may have reduced the number of eligible referents but was not of scientific importance). For the lung cancer analyses, a further limitation was that each referent's smoking habit (more than 20,10-20, 1-9 cigarettes/ day, ex-smoker (for at least 2 years), pipe smoker, life long non-smoker, or unknown) should be similar to that of the case. For both causes of death, an additional constraint - that the referents had to have been younger than the case when first exposed to asbestos-was imposed; a second set of referents for cases of mesothelioma was selected, but for lung cancer cases the referents had to be chosen as a subset of the first set. Conditional logistic regression analyses were performed using Generalised Linear Interactive Modelling (GLIM), with the PECAN option for analysing a matched case-referent series. ${ }^{16}$ A test for trend due to Armitage ${ }^{17}$ was also used.

In addition, we fitted the exponential mortality model proposed by Peto $e t$ al, ${ }^{18}$ namely: Death rate $=$ b $\times$ (years since first exposure) ${ }^{3 \cdot 2}$ for both mesotheliomas and bronchial carcinomas.

\section{Results}

Table 2 describes the cohort in terms of both year of birth and year of first employment in asbestos mines, and table 3 shows the minerals to which the 7317 members of the cohort were exposed. There were 3212 men whose only asbestos exposure was in amosite mines; of these, 1402 had had no other mining experience, but 1810 had been exposed to other minerals, usually gold, or silica, or both; 1800 men had worked only in crocidolite mines, and 1630 had been exposed to other non-asbestiform minerals, again mainly gold and silica, as well as crocidolite. Almost one tenth of the cohort (675) men had mixed asbestos exposures; most of these had worked in other mines, 500 in gold or silica.

Just over half of the cohort $59 \%$ of the 3212 of those exposed to amosite and $50 \%$ of the 3430 exposed to crocidolite) had net service under a year

Table 3 Numbers of men in the cohort according to the amphibole to which they had been exposed

\begin{tabular}{lc}
\hline Amosite: & \\
No other mineral & 1402 \\
No other asbestos & $1810^{\star}$ \\
Total & 3212 \\
& \\
Crocidolite: & 1800 \\
No other mineral & $1630 \dagger$ \\
No other asbestos & 3430 \\
Total & $675 \ddagger$ \\
"Mixed" & 7317 \\
Complete cohort & 1127 \\
\hline *Other minerals: Gold, or silica, or both & 467 \\
Some gold or silica: & 1079 \\
†Other minerals: Gold, or silica, or both & 375 \\
Some gold or silica: & $304(227) \S$ \\
†Amosite and crocidolite & $127(100)$ \\
Amosite and chrysotile & $58(34)$ \\
Crocidolite and chrysotile & $90(61)$ \\
Amosite and Transvaal crocidolite & $96(78)$ \\
Other combinations of asbestos exposure & \\
\$Figures in parentheses are of men also exposed to gold, or silica, \\
or both.
\end{tabular}


Table 4 Constitution of the cohort at the end of 1980

\begin{tabular}{lcccc}
\hline & $\begin{array}{c}\text { Amosite } \\
\text { No(\%) }\end{array}$ & $\begin{array}{l}\text { Crocidolite } \\
\text { No(\%) }\end{array}$ & $\begin{array}{l}\text { “Mixed" } \\
\text { No (\%) }\end{array}$ & $\begin{array}{l}\text { Complete } \\
\text { cohort } \\
\text { No(\%) }\end{array}$ \\
\hline Alive & $2460(77)$ & $2950(86)$ & $515(76)$ & $5925(81)$ \\
Dead & $648(20)$ & $423(12)$ & $154(23)$ & $1225(17)$ \\
Lost to view & $104(3)$ & $57(2)$ & $6(1)$ & $167(2)$ \\
Total & $3212(100)$ & $3430(100)$ & $675(100)$ & $7317(100)$ \\
\hline
\end{tabular}

and $8 \%$ had more than 10 years of service $(5 \%$ and $9 \%$ for amosite and crocidolite exposure respectively). Almost half the cohort (41\%) had accumulated less than 1 (fibres $/ \mathrm{ml}$ ) $\times$ years, and fewer than $10 \%$ had exposure of more than 30 (fibres/ $\mathrm{ml}) \times$ years. Cumulative exposure averaged $15 \cdot 2$ (fibres $/ \mathrm{ml}$ ) $\times$ years in the amosite subcohort of 3212 men and 9.6 (fibres $/ \mathrm{ml}) \times$ years among the 3430 men of the crocidolite subcohort.

Table 4 shows the vital status at the end of 1980 for the members of the cohort. By the end of follow up, 167 had been lost to view, around $2 \%$ in each subcohort. There had been 1225 deaths (17\%). The proportions of survivors were: $77 \%$ of amosite exposed; $86 \%$ of crocidolite exposed; and $76 \%$ of those with mixed exposures.

The cause of death as certified and on best available information was the same, in the study codes, in 1107 deaths $(90 \%$; see table 5$)$. The discrepancies in the distributions were mainly (a) the number of mesotheliomas (study codes 11-13) was increased from 16 to 30 ; (b) 10 additional deaths due to pneumonia (18), chronic obstructive pulmonary disease (19), asbestosis (20), or "other" and unspecified pneumoconiosis (22) were recognised, although those from silicosis (21) were reduced by five; (c) 14 more cases of ischaemic heart disease and pulmonary heart disease $(15,16)$ were identified; and (d) the "other" known causes on death certificates (26) were reduced on best evidence by 25 . For no other code was the change in numbers greater than three. A major disagreement in detail concerned lung cancer (09): of the 63 deaths certified with this diagnosis, seven were in fact mesotheliomas of the pleura, and nine additional bronchogenic carcinomas were found on best evidence. Asbestosis and mesothelioma were recorded by the CSS under one rubric until 1978; death certificates recorded 16 mesotheliomas and five deaths from asbestosis, but on best available evidence the numbers were 30 and seven, respectively. Silicosis also accounted for seven deaths on best available evidence.

Table 6 illustrates the subject-years analysis for the complete cohort. There were 331 more deaths (all causes) than expected, an excess that was of astronomic significance. Where reference rates were available, certified causes contributing to the overall excess were: tuberculosis (study code 01); malignant

Table 5 Causes of the 1225 deaths, as certified and on best available information

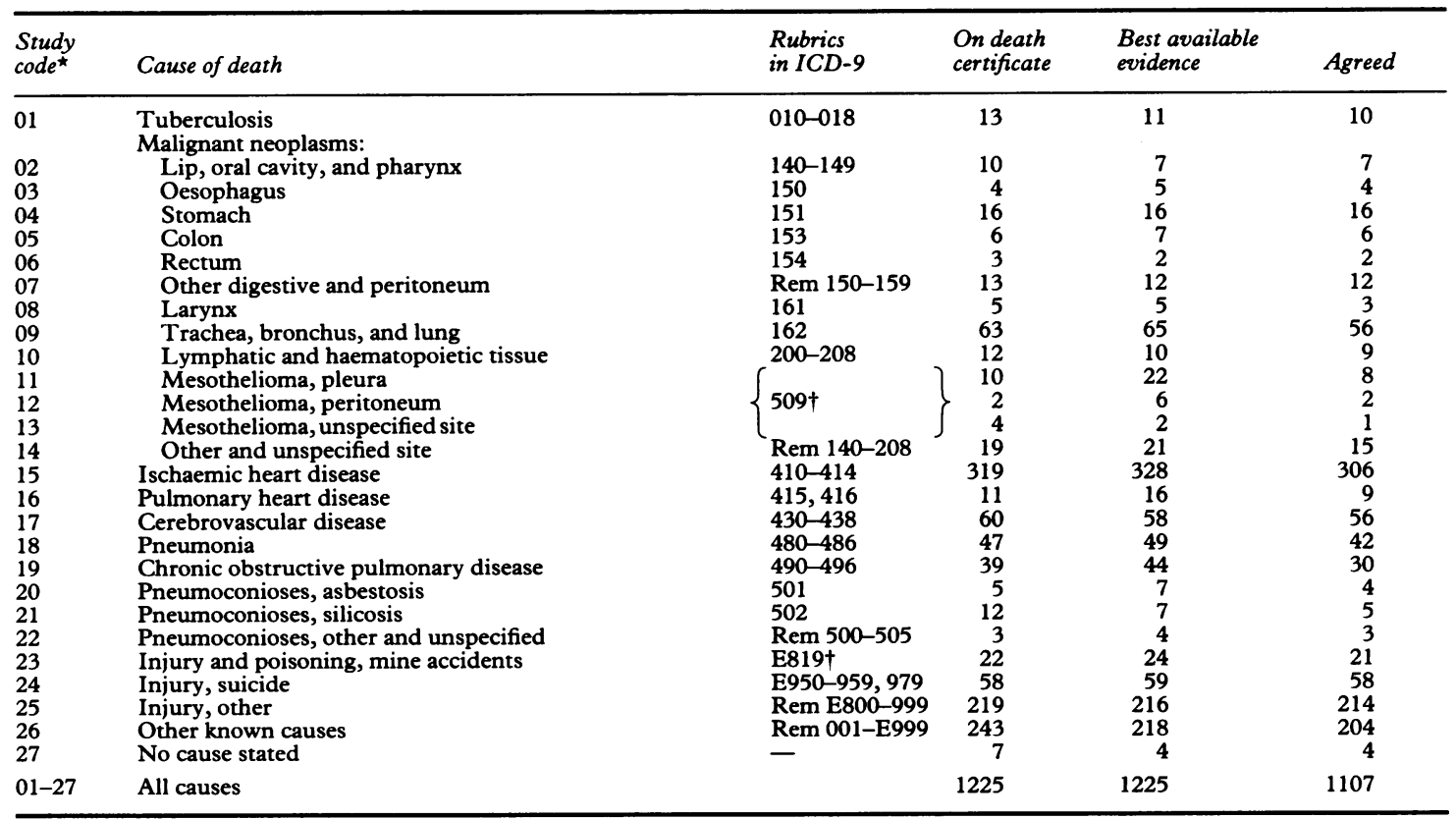


Table 6 Deaths observed $(O)$ by certified causes, excess or shortfall $(O-E)$ in relation to those expected (E) on the basis of white male mortality in South Africa (where available), and $O / E$ ratios, with $95 \%$ confidence intervals

\begin{tabular}{|c|c|c|c|c|c|}
\hline \multicolumn{2}{|c|}{ Cause of death, with study code } & \multirow{2}{*}{$\frac{O}{13}$} & \multirow{2}{*}{$\frac{O-E}{6 \cdot 1}$} & \multirow{2}{*}{$\frac{O / E}{1.90}$} & \multirow{2}{*}{$\frac{(95 \% C I)}{(1.01-3.25)}$} \\
\hline 01 & $\begin{array}{l}\text { Tuberculosis } \\
\text { Malignant neoplasms: }\end{array}$ & & & & \\
\hline 02 & Lip, oral cavity, and pharynx & 10 & $5 \cdot 3$ & $2 \cdot 14$ & $(1.03-3.94)$ \\
\hline $03-07 \star$ & All other digestive and peritoneum & 36 & $-4 \cdot 8$ & 0.88 & $(0 \cdot 62-1 \cdot 22)$ \\
\hline $08^{\star}$ & Larynx & 5 & $2 \cdot 3$ & 1.86 & $(0 \cdot 60-4 \cdot 34)$ \\
\hline $09 \star$ & Trachea, bronchus, and lung & 63 & 26.4 & $1 \cdot 72$ & $(1 \cdot 32-2 \cdot 21)$ \\
\hline 10 & Lymphatic and haematopoietic tissue & 12 & -0.8 & 0.93 & $(0.48-1.63)$ \\
\hline $11-13 \ddagger$ & Mesothelioma & 16 & $(16) \S$ & -11 & \\
\hline $14^{\star}$ & Other and unspecified site & 19 & $-17 \cdot 1$ & 0.53 & $(0.32-0.82)$ \\
\hline 15 & Ischaemic heart disease & 319 & $30 \cdot 7$ & $1 \cdot 11$ & $(0.99-1 \cdot 23)$ \\
\hline $16 \dagger$ & Pulmonary heart disease & 10 & $5 \cdot 5$ & $2 \cdot 24$ & $(1 \cdot 07-4 \cdot 12)$ \\
\hline 17 & Cerebrovascular disease & 60 & $2 \cdot 5$ & $1 \cdot 04$ & $(0 \cdot 80-1 \cdot 34)$ \\
\hline 18 & Pneumonia & 47 & 15.0 & 1.47 & $(1.08-1.95)$ \\
\hline 19 & $\begin{array}{l}\text { Chronic obstructive pulmonary disease } \\
\text { Pneumoconiosis: }\end{array}$ & 39 & $12 \cdot 8$ & $1 \cdot 49$ & $(1.06-2 \cdot 03)$ \\
\hline $20 \ddagger$ & Asbestosis & 1 & (1) & $一$ & \\
\hline $21+$ & Silicosis & 5 & $4 \cdot 3$ & $-\|$ & \\
\hline $22 \ddagger$ & Other & 0 & - & $-\|$ & \\
\hline & Injury and poisoning: & & & & \\
\hline \multirow{6}{*}{$\begin{array}{l}23 \| \\
24 \\
25 \| \\
26 \| \\
27 \|\end{array}$} & Mine accidents & 22 & $(22)$ & $-\|$ & \\
\hline & Suicide & 58 & $20 \cdot 4$ & $1 \cdot 54$ & $(1 \cdot 17-2 \cdot 00)$ \\
\hline & Other & 219 & $(115)$ & -11 & \\
\hline & Other known causes & 243 & (49) & $-\|$ & \\
\hline & No cause stated & 7 & (7) & $-\|$ & \\
\hline & $\begin{array}{l}\text { Sub total of lines } 01-27 \text { above } \\
\text { Deaths before } 1949 \text { or } 1968 \text { not included above (see footnotes) }\end{array}$ & $\begin{array}{r}1204 \\
21\end{array}$ & $\begin{array}{l}(319) \\
(12) \pi\end{array}$ & -11 & \\
\hline \multicolumn{2}{|c|}{ All causes } & 1225 & 331 & $1 \cdot 37$ & $(1 \cdot 29-1 \cdot 45)$ \\
\hline
\end{tabular}

${ }^{\star}$ Reference rates were available only for 1949-80; see text.

tReference rates were available only for 1968-80; see text.

†No reference rates were obtained; see text.

$\S$ Figures in parentheses are estimates.

$\| \mathrm{O} / \mathrm{E}$ ratios are not available or would be meaningless.

TComprising 14 deaths from pneumoconiosis, and a shortfall of two from among seven deaths from cause 07 and one from cause 16.

neoplasms of lip, oral cavity, and pharynx; larynx; and trachea, bronchus, and lung (02; 08; and 09); ischaemic and pulmonary heart disease $(15,16)$; pneumonia and chronic obstructive pulmonary disease $(18,19)$; silicosis $(21)$; and suicide (24), for which the combined excess was 129 ; this was increased to 264 from mine accidents (23) and "other" injury and poisoning (25). All 16 mesotheliomas entered on death certificates and the 14 deaths before 1968 that were ascribed on death certificates to pneumoconiosis brought the excess accounted for to 296. For causes 03-07 (considered either separately or together), 10, and 17 , findings were fairly close to expectations; but there was a shortfall of 17 for cause 14 ("other cancers"). The balance of about 55 deaths for all causes was mainly in "other known causes" (code

Table 7 Deaths observed $(O)$ by selected causes, with $O / E$ ratios and $90 \%$ confidence intervals, for amosite and crocidolite subcohorts

\begin{tabular}{|c|c|c|c|c|c|c|c|}
\hline \multirow{2}{*}{\multicolumn{2}{|c|}{ Cause of death with study code }} & \multicolumn{3}{|c|}{ Amosite } & \multicolumn{3}{|c|}{ Crocidolite } \\
\hline & & \multirow{2}{*}{$\frac{O}{8}$} & \multirow{2}{*}{$\frac{O / E}{2 \cdot 17}$} & \multirow{2}{*}{$\frac{(90 \% C I)}{(1.08-3.91)}$} & \multirow{2}{*}{$\frac{O}{4}$} & \multirow{2}{*}{$\begin{array}{l}O / E \\
1.74\end{array}$} & \multirow{2}{*}{$\frac{(90 \% C I)}{(0.59-3.98)}$} \\
\hline 01 & $\begin{array}{l}\text { Tuberculosis } \\
\text { Malignancies: }\end{array}$ & & & & & & \\
\hline 02 & Lip, oral cavity, and pharynx & 1 & 0.42 & $(0.02-1.97)$ & 5 & 2.94 & $(1 \cdot 16-6 \cdot 18)$ \\
\hline 08 & Larynx & 2 & 1.44 & $(0.25-4.52)$ & 3 & 3.09 & $(0 \cdot 84-7 \cdot 98)$ \\
\hline 09 & Trachea, bronchus, and lung & 26 & 1.38 & $(0.97-1.91)$ & 27 & 2.03 & $(1 \cdot 43-2 \cdot 80)$ \\
\hline 15 & Ischaemic heart disease & 172 & $1 \cdot 16$ & $(1 \cdot 02-1 \cdot 32)$ & 105 & 0.99 & $(0 \cdot 84-1 \cdot 17)$ \\
\hline 16 & Pulmonary heart disease & 7 & $3 \cdot 17$ & $(1.49-5.95)$ & 2 & $1 \cdot 15$ & $(0 \cdot 20-3 \cdot 61)$ \\
\hline 18 & Pneumonia & 31 & 1.82 & $(1 \cdot 32-2 \cdot 46)$ & 8 & 0.69 & $(0 \cdot 34-1 \cdot 24)$ \\
\hline 19 & Chronic obstructive pulmonary disease & 22 & 1.59 & $(1 \cdot 08-2 \cdot 27)$ & 14 & 1.47 & $(0 \cdot 89-2 \cdot 30)$ \\
\hline \multirow[t]{2}{*}{$20-22$} & Pneumoconioses & 1 & $2 \cdot 78$ & $(0 \cdot 10-13 \cdot 1)$ & 2 & 8.69 & $(1 \cdot 50-27 \cdot 3)$ \\
\hline & Injury and poisoning: & & & & & & \\
\hline \multirow{5}{*}{$\begin{array}{l}23 \| \\
24 \\
25 \| \\
26 \| \\
27 \|\end{array}$} & Mine accidents & 14 & - & & 7 & - & \\
\hline & Suicide & 35 & 1.97 & $(1 \cdot 46-2 \cdot 61)$ & 21 & 1.36 & $(0 \cdot 91-1 \cdot 96)$ \\
\hline & Other & 105 & - & & 94 & - & \\
\hline & Other known causes & 130 & - & & 74 & - & \\
\hline & No cause stated & 4 & - & & 2 & - & \\
\hline \multicolumn{2}{|c|}{ All causes } & 648 & 1.42 & $(1.33-1.51)$ & 423 & $1 \cdot 27$ & $(1 \cdot 17-1 \cdot 37)$ \\
\hline
\end{tabular}

||See footnote to table 6 . 
Table 8 Duration of asbestos exposure in deaths from mesothelioma and in referents exposed to the same type of asbestos

\begin{tabular}{|c|c|c|c|c|c|c|}
\hline \multirow{2}{*}{$\begin{array}{l}\text { Duration of } \\
\text { exposure (months) }\end{array}$} & \multicolumn{2}{|c|}{ Amosite } & \multicolumn{2}{|c|}{ Crocidolite } & \multicolumn{2}{|c|}{ "Mixed" } \\
\hline & $D^{\star}$ & $R^{\star}$ & $D$ & $R$ & $D$ & $\boldsymbol{R}$ \\
\hline $\begin{array}{c}<3 \\
3-<12 \\
12-<48 \\
48-<96 \\
96-<192 \\
\geqslant 192\end{array}$ & $\begin{array}{l}0 \\
3 \dagger \\
0 \\
0 \\
0 \\
1\end{array}$ & $\begin{array}{l}5 \\
6(1) \\
5 \\
4(2) \\
1 \\
-\end{array}$ & $\begin{array}{l}0 \\
0 \\
5 \\
1 \\
6 \\
8\end{array}$ & $\begin{array}{r}7 \\
16 \\
16 \\
8 \\
15 \\
17\end{array}$ & $\begin{array}{l}0 \\
1 \\
1 \\
1 \dagger \\
0 \\
3\end{array}$ & $\begin{array}{l}0 \\
0 \\
3(1) \\
4 \\
5(1) \\
0\end{array}$ \\
\hline Total & 4 & 21 & 20 & 79 & 6 & 12 \\
\hline
\end{tabular}

*Columns headed $D$ and $R$ give the numbers of deaths from mesothelioma and the numbers of referents respectively. For each case, up to six referents were chosen as men who lived to a greater age than the case and who, except for five, indicated in parentheses, were first exposed to asbestos earlier in life than the case. Without these five, one case of those marked with a dagger $(\dagger)$ with amosite and one ( $\dagger$ ) with "mixed" exposure would have had to be excluded; their five referents were first employed at only slightly older ages than the respective cases.

26); this was about one quarter more than the number expected.

Table 7 summarises the corresponding analyses for the amosite and crocidolite subcohorts of 3212 and 3430 miners respectively; $\mathrm{O} / \mathrm{E}$ ratios are given only for those causes of death identified in the previous paragraph as in excess for the whole cohort, but all the study codes were examined in both subcohorts; there were no other considerable excesses. In view of the lower statistical power due to the much smaller numbers of deaths, interval estimates of $\mathrm{O} / \mathrm{E}$ ratios are quoted at $90 \%$ confidence. Apart from mine accidents, other injury, and poisoning, and other known causes (codes 23, 25, and 26), there were no clear excesses in both subcohorts, although several causes of death were in undoubted excess in one subcohort or the other.

Conditional logistic regression analyses, based on the first selection of referents (without constraint on age of starting asbestos employment), were carried out on: (a) the 17 deaths among crocidolite miners that best available evidence indicated were due to pleural mesothelioma and all 68 referents sought; (b) the 30 deaths among those exposed to amosite caused, on best evidence, by bronchogenic cancer and 113 referents, of 120 sought; and (c) the 22 lung cancer cases in the crocidolite subcohort and 75 (of 88) referents. For all three analyses, the variables entered into the regression one at a time were: net service; gross service; cumulative exposure; average concentration; and residence time. In each analysis, net service was the variable with the largest likelihood ratio (LR) statistic, and all three were of unquestionable significance, whereas the other variables, when included as well as net service, had very small effects. The model fitted in these analyses was of the form: Relative risk $=\exp (\beta \times$ years of net service), and the values of $\beta$ in the three analyses were: (a) 0.15 , (b) 0.08 , and (c) 0.25 . From the last, the lung cancer risk after 10,20 , and 30 years service would be about 12 times, 150 times, and 1800 times the risk in the unexposed. As this background risk is not negligible, the estimated relative risks are seriously misleading. They arose because many of the referents for all three analyses were too old when they started work for disease to have developed before the end of follow up. To avoid this problem, it was necessary to constrain the referents additionally to have been younger than the relevant case when first exposed to asbestos.

Table 8 compares the duration of exposure to asbestos of the 30 mesothelioma cases and 112 referents (of 180 sought) selected in this way, with some minor relaxations of the constraint on referents for one amosite and one "mixed" case (see footnote to table 8). Twenty of the cases had worked on crocidolite mines; no case of mesothelioma occurred with less than 12 months of exposure to crocidolite, although such short durations were not uncommon among the referents. The test ${ }^{17}$ for trend in the crocidolite columns yielded a $\chi^{2}$ statistic (1 degree of freedom) of 5.55; conditional logistic regression again identified net service as the variable with the highest LR statistic, but at 3.81 it was lower than from the simpler test for trend. Four of the 30 cases had worked in amosite mines, and six had had exposure to "mixed" asbestos. None of these 10 cases developed their tumour after less than three months of exposure.

When superimposed on sets (b) and (c), the constraint on age at which exposure to asbestos started reduced the numbers available for analysis drastically, to 23 and 10 deaths in amosite and crocidolite miners, and 49 and 17 referents. Table 9

Table 9 Duration of asbestos exposure in deaths from lung cancer and in referents exposed to the same type of asbestos

\begin{tabular}{lrrrrrr}
\hline & \multicolumn{2}{l}{ Amosite } & & \multicolumn{2}{c}{ Crocidolite } \\
\cline { 2 - 3 } \cline { 5 - 6 } Duration of exposure (months) & $D^{\star}$ & $R^{\star}$ & & $D$ & $R$ \\
\hline$<3$ & 3 & 16 & & 0 & 3 \\
$3-<12$ & 6 & 6 & & 2 & 2 \\
$12-<48$ & 5 & 12 & & 4 & 7 \\
$48-<96$ & 1 & 4 & 2 & 3 \\
$96-<192$ & 6 & 6 & & 2 \\
$\geqslant 192$ & 2 & 5 & 1 & - \\
Total & 23 & 49 & 10 & 17 \\
\hline
\end{tabular}

*Columns headed $D$ and $R$ give the numbers of deaths from lung cancer and the numbers of referents respectively. For each case, up to four referents were first chosen as men who lived to a greater age than the case and who had had similar smoking habits. This primary selection, for the purposes of logistic regression, was of 113 referents for 30 deaths in the amosite subcohort, and 75 referents for 22 cases exposed to crocidolite; because logistic regression would not have been feasible on the small numbers with "mixed" exposures, no referents were chosen. In a secondary selection, referents were excluded unless they had been first exposed to asbestos earlier in life than the case. 
Table 10 Mortality from lung cancer and mesothelioma fitted by exponential model ${ }^{17}$

\begin{tabular}{|c|c|c|c|c|c|}
\hline & \multicolumn{5}{|c|}{ Years since first exposure to asbestos } \\
\hline & $<10$ & $10-<20$ & $20-<30$ & $\geqslant 30$ & All years \\
\hline \multirow{5}{*}{$\begin{array}{l}\text { Amosite ( } 3212 \text { men): } \\
\text { Subject-years }(1000) \\
\text { mesothelioma } b=1.30 \times 10^{-8} \\
\text { Deaths modelled } \\
\text { Deaths observed } \\
\text { lung cancer } b=9.83 \times 10^{-8} \\
\text { Deaths modelled } \\
\text { Deaths observed }\end{array}$} & & & & & \\
\hline & $27 \cdot 6$ & $17 \cdot 0$ & $6 \cdot 0$ & 0.5 & $51 \cdot 1$ \\
\hline & $\begin{array}{l}0 \cdot 10 \\
0\end{array}$ & $\begin{array}{l}1 \cdot 30 \\
1\end{array}$ & $\begin{array}{l}2 \cdot 08 \\
2\end{array}$ & $\begin{array}{l}0.51 \\
1\end{array}$ & $\begin{array}{l}4 \\
4\end{array}$ \\
\hline & & & & & \\
\hline & $\begin{array}{l}0.80 \\
3\end{array}$ & $\begin{array}{l}9 \cdot 79 \\
10\end{array}$ & $\begin{array}{l}15 \cdot 63 \\
14\end{array}$ & $\begin{array}{l}3 \cdot 78 \\
3\end{array}$ & $\begin{array}{l}30 \\
30\end{array}$ \\
\hline \multirow{4}{*}{$\begin{array}{l}\text { Crocidolite ( } 3430 \text { men): } \\
\text { Subject-years }(1000) \\
\text { mesothelioma } b=10.51 \times 10^{-8} \\
\text { Deaths modelled } \\
\text { Death observed } \\
\text { lung cancer } b=11.49 \times 10^{-8} \\
\text { Deaths modelled } \\
\text { Deaths observed }\end{array}$} & & & & & \\
\hline & $27 \cdot 8$ & $13 \cdot 6$ & $3 \cdot 3$ & $0 \cdot 2$ & $44 \cdot 9$ \\
\hline & $\begin{array}{l}0.82 \\
2\end{array}$ & $\begin{array}{l}8.09 \\
8\end{array}$ & $\begin{array}{c}8 \cdot 85 \\
10\end{array}$ & $\begin{array}{l}2 \cdot 24 \\
0\end{array}$ & $\begin{array}{l}20 \\
20\end{array}$ \\
\hline & $\begin{array}{l}0.89 \\
2\end{array}$ & $\begin{array}{l}8 \cdot 87 \\
9\end{array}$ & $10^{9 \cdot 76}$ & $\begin{array}{l}2 \cdot 47 \\
1\end{array}$ & $\begin{array}{l}22 \\
22\end{array}$ \\
\hline \multirow{3}{*}{$\begin{array}{l}\text { "Mixed" (675 men): } \\
\text { Subject-years }(1000) \\
\text { mesothelioma } b=8 \cdot 17 \times 10^{-8} \\
\text { Deaths modelled } \\
\text { Deaths observed }\end{array}$} & & & & & \\
\hline & $6 \cdot 4$ & $4 \cdot 4$ & $1 \cdot 4$ & $0 \cdot 1$ & $12 \cdot 3$ \\
\hline & $\begin{array}{l}0 \cdot 17 \\
0\end{array}$ & $\begin{array}{l}2 \cdot 12 \\
3\end{array}$ & $\begin{array}{l}3.06 \\
3\end{array}$ & $\begin{array}{l}0.65 \\
0\end{array}$ & $\begin{array}{l}6 \\
6\end{array}$ \\
\hline
\end{tabular}

shows the distributions by duration of exposure to asbestos; for each type of fibre a slight positive association was found between risk of lung cancer and duration of employment.

Table 10 shows the results of fitting the exponential model to deaths ascribed on best evidence to mesothelioma and lung cancer, distinguishing amosite, crocidolite, and "mixed" exposures. Of the six peritoneal mesotheliomas, one was exposed only to amosite, two only to crocidolite, and one to both amosite and crocidolite; two occurred in the group of 90 subjects exposed to amosite and Transvaal crocidolite. Table 11 shows the intervals between the first exposure to asbestos and death due to mesothelioma for these six tumours, and also for the 17 pleural mesotheliomas in the crocidolite subcohort, and for the remaining seven mesotheliomas.

\section{Discussion}

As already mentioned, the identification of the cohort is thought to have been almost complete, and the

Table 11 Interval between first asbestos employment and death from mesothelioma

\begin{tabular}{llll}
\hline & $\begin{array}{l}\text { Peritoneal } \\
\text { Interval }(y)\end{array}$ & $\begin{array}{l}\text { Pleural tumours } \\
\text { after crocidolite } \\
\text { exposure }\end{array}$ & $\begin{array}{l}\text { All other } \\
\text { mesotheliomas }\end{array}$ \\
\hline$<5$ & 0 & 0 & 0 \\
$5-<10$ & 0 & 2 & 0 \\
$10-<20$ & 0 & 7 & 5 \\
$20-<30$ & 5 & 8 & 2 \\
$\geqslant 30$ & 1 & 0 & 0 \\
Total & 6 & 17 & 7 \\
\hline
\end{tabular}

work histories of the 7317 men were accurate; the median age of starting asbestos mining was around 25 years in each decade of first employment (table 2). Information on fibre concentrations, however, especially before 1970 , is suspect, although probably better than extrapolations from midget impinger counts, which have had to be relied on in so many historical studies of asbestos workers.

It is noteworthy that about $90 \%$ of the cohort who had worked in non-asbestos mines had been exposed to free crystalline silica (see table 3), a suspect carcinogen. The gold mining service, particularly for the amosite miners, was almost entirely on Witwatersrand gold mines, where there was also exposure to low levels of radiation, due to the presence of radon daughters. The possible effect of exposure to silica and radon daughters on mortality from lung cancer had therefore to be considered. For amosite and for crocidolite workers, rates of death from lung cancer were calculated, by years since first exposure, for those with and without exposure in non-asbestos mines, but no consistent differences were found. Several other analyses were extended in like fashion, but we could find no evidence that additional exposure to silica and radon had any effect on mortality from lung cancer.

The group of 90 men who had been exposed to Transvaal crocidolite (and also to amosite, see table 3 ) formed only $1.2 \%$ of the cohort, but they accounted for 36 deaths, or $2.9 \%$ of the 1225 in the entire cohort. This group was 10 years older on average than the complete cohort, but that is not sufficient reason to account for their seven deaths ascribed to bronchial carcinoma $(11 \cdot 1 \%$ of the total of 63) and (on best evidence) two mesotheliomas- 
both peritoneal - and two deaths due to asbestosis (of six and seven respectively, in the entire cohort). Little is known of dust conditions in these crocidolite mines in Transvaal, but, at least on walk through inspection, their mills were extremely dusty.

Unfortunately, more detailed investigation of this phenomenon is one of several tasks that have become unfeasible because of an imposed incompatibility of computer software. Another such task is the investigation of the excess mortality from "other" known causes (code 26, see tables 6 and 7): the numbers of deaths expected can only be approximated, but the $\mathrm{O} / \mathrm{E}$ ratio for the complete cohort can be estimated from table 6 as $243 /(243-49) \approx 1 \cdot 25$, with similar estimates for both the subcohorts. In most cohorts of asbestos workers, although there have been excesses, sometimes very large, from asbestos related causes, mortality from the group of

\begin{tabular}{lllr}
\hline & Amosite & Crocidolite & Ratio \\
\hline Incidence per 100 000 subject-years & $4 / 0 \cdot 51=7.8$ & $20 / 0.45=44 \cdot 6$ & $5 \cdot 7$ \\
Proportional mortality ratio (PMR) & $4 / 648=0.6 \%$ & $20 / 423=4.7 \%$ & $7 \cdot 7$ \\
PMR in men followed from 20 years after first employment & $3 / 172=1 \cdot 7 \%$ & $10 / 84=11 \cdot 9 \%$ & $7 \cdot 0$ \\
Values of $b$ 10 & $1 \cdot 30$ & 10.51 & $8 \cdot 1$ \\
Values of $b$ adjusted for average exposure & $\alpha 1 \cdot 30 / 15 \cdot 2$ & $\alpha 10.51 / 9 \cdot 6$ & $12 \cdot 8$ \\
\hline
\end{tabular}

causes called "other" has been lower than expectation. This was not true in the present study, and no explanation can be offered at this stage; however, extension of the study, by follow up to at least the end of 1990 with a more detailed breakdown of cause of death is seen to be of great importance.

Several excesses were shown by subject years analysis in the complete cohort (table 6), and most of the corresponding SMRs were increased in either the amosite or crocidolite subcohort, or both, although appearing of low statistical significance because of the much smaller numbers of deaths (table 7). The SMRs calculated for the 1617 men who had completed their exposure before 1961 showed similar excesses-namely, for total mortality (all causes), tuberculosis, cancer of lung and bronchus, pneumonia, and chronic obstructive pulmonary disease. The SMR for carcinoma of the buccal cavity and pharynx was $1 \cdot 74$, but based on only two deaths.

The SMRs for lung cancer were 1.38 and $2 \cdot 03$, for amosite and crocidolite respectively (table 7). Although the numbers of deaths recorded on death certificates were inflated by deaths found on best evidence to be from mesothelioma, the numbers were balanced by deaths due to lung cancer certified as due to other causes (table 5). Each SMR fell outside the $90 \%$ confidence interval of the other, so the SMR for crocidolite can be taken as substantially higher than that for amosite, despite the lower average cumulative exposure. The difference was maintained when SMRs were calculated from 20 years from first employment (amosite 1.08; crocidolite 1.67).

Incidence in any particular cohort can be summar- ised by the fitted parameter $\boldsymbol{b}$ in the exponential mortality model ${ }^{18}$; indeed $b$ reflects both the average exposure (some combination of duration and intensity) and the toxicity of fibre of the specific type. The relative toxicity for lung cancer of amosite and crocidolite may be estimated heuristically by dividing the ratio of the values of $b$ (see table 10) by the ratio of average cumulative exposure: this gives $(11.49) /(9.83) \div(9.6) / 15 \cdot 2)$, or 1.85 , as a rough indication of the relative toxicity of crocidolite compared with amosite.

Best evidence showed 30 mesotheliomas, of which four, 20, and six were among men in the amosite, crocidolite, and "mixed" subcohorts respectively. The relative toxicity for these tumours of amosite and crocidolite can be evaluated by several methods leading to the estimates, of increasing reliability, in the final column below:

Although no precision can be claimed for them, the ratios above show clearly that crocidolite has a toxicity for mesothelioma about an order of magnitude higher than that for amosite. This is much more convincing evidence than any available previously, which has had to be culled from comparisons across a very few studies of exposures to a single fibre type. ${ }^{19} 20$ Even the evidence of proportional mortality is sufficient, however, for confidence that chrysotile is much less toxic for mesothelioma even than amosite; PMRs in five chrysotile studies averaged $0.2 \%$, the highest being only $0.3 \%$, whereas in three amosite cohorts the PMRs varied from $1.5 \%$ to $4.6 \% .^{19} 20$

None of the 30 cases of mesothelioma had exposure to asbestos of less than three months (amosite and "mixed") or of less than 12 months (crocidolite; see table 8). Too few cases existed for any analysis except for exposure to crocidolite, where a test for trend provided a significant $\chi^{2}$ statistic. As in all other cohorts of asbestos workers in which mesotheliomas have been found, the intervals between the first asbestos employment and death from mesothelioma have been long; only two of the 30 intervals shown in table 11 were less than 10 years. One of the men concerned had spent his whole life in the asbestos mining region, where considerable aerial contamination with asbestos occurred in many areas; it is more likely that his mesothelioma was due to environmental pollution from childhood than to occupational exposure for only seven years. The other short interval was of less than nine years; this man does not seem to have suffered exposure to asbestos before 
starting crocidolite mining.

Excesses of deaths from tuberculosis occurred in both subcohorts, more definite after exposure to amosite (table 7); the excesses were, however, considerably smaller than in Wittenoom crocidolite miners. ${ }^{7}$ An increased SMR for carcinoma of buccal cavity and pharynx in the complete cohort was not seen in those exposed to amosite; the SMR in the crocidolite cohort was raised, but on small numbers, and there were four deaths from this condition in those with "mixed" exposures.

It is notable that no excesses were found for cancer of oesophagus, stomach, colon, or rectum. In the Wittenoom study, there were no significant excesses of cancers in the "upper aerodigestive tract", " and in an earlier report on United States amosite factory workers the SMR of $7 / 3.65=1.92 \mathrm{had}$ a wide $95 \%$ confidence interval (0.77-3.95).$^{10}$ In both of these studies the fibre concentrations were very high.

The large SMR for ischaemic heart disease in the entire cohort is explained by the excess in amosite miners, who also had a particularly high SMR for suicide (tables 6 and 7). This suggests that the amosite workers had had a more reckless lifestyle than those in the crocidolite mines. A higher proportion of the amosite miners had worked on gold mines (table 3), and the finding is in line with that from a study in South African gold miners showing excess mortality for both causes of death. ${ }^{21}$

Excess mortality from pneumonia among the amosite miners, but not in the crocidolite subcohort, is based on such large numbers that the SMR of 1.82 (table 7) is associated with a (two sided) p-value of 0.004 . It is unlikely that exposure to amosite leads directly to pneumonia, and no explanation for the excess can be offered.

There is no evidence that asbestos per se causes chronic obstructive pulmonary disease, although an obstructive pattern is not uncommonly found in persons exposed to asbestos. Smoking is probably a major contributing factor. ${ }^{22}{ }^{23}$ Significant excesses of COPD have been reported in the crocidolite miners in Western Australia ${ }^{24}$ and in United States amosite factory workers. ${ }^{10}$ Although SMRs for this rubric, and for the closely associated pulmonary heart disease, were increased in the current study (tables 6 and 7), no associations could be found with measures of exposure to asbestos.

\section{Conclusions}

Even by the end of follow up, over $85 \%$ of this cohort were less than 65 years of age, and most of these men were still living. Nevertheless, the 1225 deaths that were found were considerably more than expected on the basis of the mortality of white South African males, although the average period of exposure to asbestos had been short. Although bronchial carcinoma, mesothelioma, and asbestosis contributed to this excess, there were also contributions from several other causes, particularly in those exposed to amosite, who it seems followed a rather destructive life style.

Of particular note is the comparatively low risk of mesothelioma in amosite workers. There can now be no question that crocidolite is far more dangerous than amosite at least in so far as mesothelioma is concerned. Also important is the exposure-response relation between net service in crocidolite mines and risk of mesothelioma. Fortunately, these last statements can be made without relying on the subject-years analyses, with their potential weakness due to unexplained excess of mortality from "other" causes. Nevertheless, the need to extend and refine the follow up is re-emphasised.

\section{Appendix}

MEASUREMENTS OF EXPOSURE

Before 1970, counts were infrequent-at about five year intervals-but thereafter at least every two years. Measurements were made by Konimeter until 1965; all particles of less than $5 \mu \mathrm{m}$ diameter and aspect ratio of 2 or more were counted, a maximum length of $200 \mu \mathrm{m}$ being specified in 1950 . The thermal precipitator was used from 1965 to 1975 . To be counted, a particle had to have an aspect ratio of at least 3 and a length of $5 \mu \mathrm{m}$ or more. In 1970 the maximum diameter was reduced to $3 \mu \mathrm{m}$ and the maximum length to $100 \mu \mathrm{m}$. In 1975 , the international membrane filter method ${ }^{25}$ was introduced for routine hygiene surveillance.

Graphs of the mean fibre concentrations in a mine at different calendar times since the inception of measurements were drawn up for most mines. In 1970, extensive studies were carried out using the membrane filter method to establish in effect a mean fibre count for every possible occupation in each year of the study. The work histories we had obtained were coded chronologically as to mine, species of asbestos, and occupation, and every subject's exposure to asbestos fibre was computed by occupation and calendar time. These computed exposures were summed over the subject's asbestos mining career to give the cumulative exposure (in fibres $/ \mathrm{ml} \times$ years) to amosite and crocidolite separately. We also calculated for each man the gross and net duration of exposure to asbestos, termed gross and net service, and the interval from his first exposure to asbestos until his death or loss to view, or to the end of follow up; this interval is sometimes called residence time.

For the logistic regression analyses, the summations for each case's referents were made only up to the case's age at death.

Requests for reprints to: Dr G K Sluis-Cremer, Epidemiology Research Unit, Medical Bureau for 
Occupational Diseases, 144 De Korte Street, Braamfontein, 2001 Republic of South Africa.

1 McDonald JC, Liddell FDK, Gibbs GW, Eyssen GE, McDonald AD. Dust exposure and mortality in chrysotile mining, 1910-1975. Br J Ind Med 1980;37:11-24.

2 Gardner MJ, Winter PD, Pannett B, Bennett C. Follow-up study of workers manufacturing chrysotile asbestos cement products. Br J Ind Med 1986;43:726-32.

3 Thomas HF, Benjamin IT, Elwood PC, Sweetnam PM. Further follow-up study of workers from an asbestos cement factory. Br J Ind Med 1982;39:273-6.

4 Newhouse ML, Sullivan KR. A mortality study of workers manufacturing friction materials, 1941-86. Br J Ind Med 1989;46:176-9.

5 Acheson ED, Gardner MJ, Pippard EC, Grime LP. Mortality of two groups of women who manufactured gasmasks from chrysotile and crocidolite asbestos: a 40 year follow up. $\mathrm{Br} J$ Ind Med 1982;39:344-8.

6 McDonald AD, Fry JS, Woolley AJ, McDonald JC. Dust exposure and mortality in an American chrysotile textile plant. $\mathrm{Br} J$ Ind Med 1983;40:361-7.

7 De Klerk NH, Armstrong BK, Musk AW, Hobbs MST. Cancer mortality in relation to measures of occupational exposure to crocidolite at Wittenoom Gorge in Western Australia. Br J Ind Med 1989;46:529-36.

8 Jones JSP, Smith PG, Pooley FD, Berry G, et al. The consequences of exposures to asbestos dust in a war-time gasmask factory. In Wagner JC, ed. Biological effects of mineral fibres. Lyon: International Agency for Research on Cancer, 1980:637-53.

9 McDonald AD, McDonald JC. Mesothelioma after crocidolite exposure during gasmask manufacture. Environ Res 1978;17:340-6.

10 Seidman H, Selikoff IJ, Hammond EC. Short term asbestos work exposure and long term observation. Ann NY Acad Sci 1979;300:61-89.

11 Acheson ED, Gardner MJ, Winter PD, Bennett C. Cancer in a factory using amosite asbestos. Int $J$ Epidemiol 1984;13:3-10.

12 Berry G. The analysis of mortality by the subject-years method. Biometrics 1983;39:173-84.
13 Liddell FDK. The development of cohort studies in epidemiology: a review. J Clin Epidemiol 1988;41:1217-37.

14 Marsh GW, Preminger M. A user-orientated occupational cohort mortality analysis program. American Statistician 1980;34:245-6.

15 Liddell FDK. Simple exact analysis of the Standardised Mortality Ratio. J Epidemiol Community Health 1984;38:85-8.

16 Baker RJ, Nelder JA. The GLIM system, release 3. Oxford: Numerical Algorithms Group, 1978.

17 Armitage P, Berry G. Statistical methods in medical research. 2nd ed. Oxford: Blackwell, 1987:372-4.

18 Peto J, Seidman H, Selikoff IJ. Mesothelioma mortality in asbestos workers: implications for models of carcinogenesis and risk assessment. Brit J Cancer 1982;45:124-35.

19 McDonald AD, McDonald JC. Epidemiology of malignant mesothelioma. In: Antman K, Aisner J, eds. Asbestos-related malignancy. Orlando, Florida: Grune and Stratton, 1986: 41-56.

20 Liddell D. Epidemiological observations on mesothelioma and their implications for non-occupational exposure to asbestos. In Spengler JD, Özkaynak H, McCarthy JF, Lee H, eds. Symposium on health effects of exposure to asbestos in buildings 14-16 December, 1988. Cambridge MA: Harvard University Energy and Envioronmental Policy Center, 1988:47-69.

21 Wyndham $\mathrm{CH}$, Bezuidenhout BN, Greenacre MJ, SluisCremer GK. Mortality of middle aged white South African gold miners. Br J Ind Med 1986;43:677-84.

22 Fournier-Massey G, Becklake MR. Pulmonary function profiles in Quebec asbestos workers. Bulletin de Physio-pathologie Respiratoire 1975;11:429-45.

23 Ohlson C, Rydman T, Sundell L, Bodin L, Hogstedt C. Decreased lung function in long-term asbestos cement workers: a cross-sectional study. Am J Ind Med 1984;5:359-66.

24 Cookson WOC, Musk AW, Glancy JJ, DeKlerk NH, Yin R. Compensation, radiographic changes and survival in applicants for asbestosis compensation. $\mathrm{Br} J$ Ind Med 1985;42:461-8.

25 Asbestosis Research Council. The management of asbestos dust by the membrane filter method: technical note 1. Rochdale: Asbestosis Research Council, 1968 (rev 1971.)

Accepted 11 November 1991

\section{Destruction of manuscripts}

From 1 July 1985 articles submitted for publication will not be returned. Authors whose papers are rejected will be advised of the decision and the manuscripts will be kept under security for three months to deal with any inquiries and then destroyed. 